\section{DRUG UTILIZATION PATTERN DURING PREGNANCY IN NORTH INDIA}

\author{
RASHMI SHARMA, BHUVNESHVAR KAPOOR, UJALA VERMA
}

ABSTRACT

BACKGROUND: Pregnancy is a special physiological condition, where drug treatment presents a special concern. AIMS: To evaluate the drug utilization pattern during pregnancy and to evaluate the effect of the educational and economic status on it.. DESIGN: The retrospective cross-sectional study. SETTING: The postgraduate Department of Pharmacology and Therapeutics of a medical college. and the antenatal clinic of the institution. MATERIALS AND METHODS: Medical students filled 405 questionnaires after interviewing pregnant women (243 primigravida and 152 multigravida). All the collected questionnaires were analysed for various study parameters. STATISTICAL ANALYSIS USED: Inter-group comparison was done using chi-square test. $P$ value $<0.05$ was considered statistically significant. RESULTS: A total of 700, 1086 and 686 drugs, with an average of 1.73, 2.89 and 2.49 drugs per pregnant women, were used during first, second and third trimester of pregnancy, respectively. A majority of the drugs used, were from category-A, followed by category$B$ and category-D. However, category $C$ and $X$ drugs constituted 2.90 (20) and $5.71 \%$ (40) of drugs used during the third trimester and first trimester, respectively. Herbal/ homeopathic drugs constituted 6.42 (45), 3.68 (40) and 1.46\% (10) of the drugs used in the first, second and third trimester of pregnancy, respectively $(P=649) .33 .33 \%$ (135) women believed that drug use during pregnancy is dangerous to both mother and child and $37.03 \%$ (150) believed that drugs are dangerous throughout pregnancy. $55.55 \%$ (225) females advocated the use of iron/folic acid during pregnancy. $24.69 \%$ (100) of women had knowledge about barrier contraceptives. Self-medication and homeopathic/ herbal drugs use was found more in graduates than in undergraduates; as well as, it was more in the higher socioeconomic group than the lower socioeconomic group. CONCLUSION: There is a need to educate and counsel women of child-bearing age, regarding the advantages and disadvantages of drug use during pregnancies, with special reference to alternative therapies and self-medication.

Key words: (Pregnancy or prenatal care/standards), (prescriptions, drug utilization, drug/statistics and numerical data or drug utilization/trends or drug utilization/statistics and numerical data or drug utilization review/methods or (drug utilization and pharmacoepidemiology/methods), (food and drug administration) classification, humans
Drugs play an important role in improving human health and promoting well-being. However, to produce the desired effect, they have to be safe, efficacious and have to be used rationally. In pregnancy, drug treatment presents a special concern due to the threat of potential teratogenic effects of the drug and physiologic adjustments in the mother, in response to pregnancy. However, it has been documented that congenital abnormalities caused by human teratogenic drugs accounts for less than $1 \%$ of total congenital abnormalities. ${ }^{[1]}$ About $8 \%$ of pregnant women need permanent drug treatment due to various chronic diseases and pregnancy-induced complications. ${ }^{[1]}$ Moreover in India, due to easy availability of drugs coupled with inadequate health services, increased proportions of drugs are used as self medication (for common complains and infective conditions), as compared to the prescribed drugs. ${ }^{[2]}$ Hence, these consumers always face the threat of adverse drug reactions and drug interactions between active hidden ingredients of both herbal and allopathic drugs. Pharmacoepidemiological studies can help in minimizing the inherent risk of drug use in pregnancy, by establishing a profile of drug consumption, by evaluating the existing health services and by investigating the interventional measures. ${ }^{[3]}$ We could not find any study demonstrating the drug utilization pattern in pregnant women in India on PubMed search (Key words: drug utilization in pregnant women in India, prescribing patterns during pregnancy in India). Hence, the present study was conducted to evaluate the drug utilization pattern during pregnancy in north India.

\section{MATERIALS AND METHODS}

The present retrospective randomized crosssectional study (each women was interviewed only once, regarding drugs used in thei present pregnancy since conception) was conducted in the Postgraduate Department of Pharmacology and Therapeutics of a Government Medical College, as practical training of fifth semester medical students to study drug utilization practices during pregnancy, in women attending the ante-nata clinic of the institution. The study was conducted after taking permission from the institutional review board. Before starting the study, ninety eight medical students were trained in pharmacokinetic and pharmacodynamic changes in pregnancy and rational prescribing, by using audio-visual aids and giving therapeutic exercises. All the students were divided into twenty groups of five each, except the last group (three students). Two groups were alloted to each teacher (senior and junior residents) and written questionnaires were distributed to the student (Anexure-1). Each student had to fill five questionnaires after interviewing pregnan women attending the out patient ante-nata clinic of the institution. Each group of students had to visit the ante-natal clinic on a fixed day of the week. Pregnant women were interviewed in local language, afte taking their well-informed written consent. Each student had to interview only one pregnant women per day. The women's statements were also confirmed from the written record, if available with them. No overlapping of the pregnant women was allowed and the study was carried over a period of six months, with effect from June 
2005 to December 2005. At the end of the study, only eighty one students submitted their questionnaires by $15^{\text {th }}$ of Jan 2006 . Students coming afterwards were not entertained, in order to avoid the chances of manipulations (copying from fellow students) from the student's side. Hence, a total of 405 questionnaires were collected and analysed for various study parameters like; educational status, duration of pregnancy, family income per capita per month, time of first antenatal visit, number of antenatal visits, self medication practices, number of drugs used, number of herbal/homeopathic drugs used, knowledge about contraceptives and knowledge about drug use during pregnancy.

All drugs used during the first (first 12 weeks), second $\left(13^{\text {th }}\right.$ to $24^{\text {th }}$ week) and third ( $24^{\text {th }}$ week onwards) trimester of pregnancy were further classified into category-A, category-B, category-C, category-D and category- $\mathrm{X}$, according to the classification for drug use during pregnancy, introduced by the US Food and Drug Administration (FDA) in 1979. ${ }^{[4]}$ The category-A includes drugs that have shown no risk to the foetus after adequate, wellcontrolled studies in pregnant women. For drugs in the category $B$, animal studies have revealed no evidence of harm to the foetus or any adverse effect, but adequate and wellcontrolled studies in pregnant women have failed to demonstrate a risk to the fetus. The category $\mathrm{C}$ includes the drugs, which have shown an adverse effect in animal studies or no animal studies have been conducted and there are no adequate and well-controlled studies in pregnant women. For drugs in the category $D$, there is positive evidence of human fetal risk, but the benefits from use in pregnant women may be acceptable despite the risk (e.g., in a life-threatening situation). However, drugs with classification $X$ are "contraindicated in pregnancy".

All the pregnant women were further divided into two groups according to educational status i.e., graduates and under- graduates and into three groups according to economic status i.e., income class-A (per capita income between Rs. 500-999/month), income class-B (per capita income between Rs. 1000-2500/ month) and income class-C (per capita income more than Rs. 2500/ month). Various parameters like self medication practices, use of herbal and homeopathic drugs, number of antenatal visits, knowledge about contraception and knowledge about drug use during pregnancy, were compared between graduates and under- graduates and among the three income groups.

\section{STATISTICAL ANALYSIS}

Results were expressed in percentage and inter-group comparison (between graduates vs under-graduates and among the three economic groups) was done using chi-square test. Different categories of drugs used during first, second and third trimester, were also compared using chi-square test. $P$-value $<0.05$ was considered statistically significant.

\section{RESULTS}

A total of 405 (243 primigravida and 152 multigravida) pregnant women were interviewed [Table 1]. $7.40 \%$ (30), $24.69 \%$ (100) and $67.90 \%(275)$ women were in the first, second and third trimester of pregnancy,
Table 1: Characteristics of study population

\begin{tabular}{|c|c|c|c|}
\hline Parameter & \multicolumn{3}{|c|}{ Number of subjects (\%) } \\
\hline $\begin{array}{l}\text { Education status } \\
\text { Duration of preanancy }\end{array}$ & Graduates:185 (45.68) & Undergraduates: 220 (54.32) & \\
\hline Duration of pregnancy & First trimester $30(7.40)$ & Second trimester100 (24.69) & Third trimester 275 (67.90) \\
\hline Gravida & Primi: 243 (60) & Multi: $152(40)$ & \\
\hline $\begin{array}{l}\text { Family income per } \\
\text { capita per month }\end{array}$ & Income class-A205 (50.62) & Income class-B 155 (38.27) & Income class-C 45 (11.11) \\
\hline Time of first ANC & First trimester 200 (49.38) & Second trimester 180 (44.44) & Third trimester 25 (6.17) \\
\hline Total number ANCs & Less than $3: 70(17.28)$ & 3 to $5: 110(27.16)$ & More than 5: 225 (55.55) \\
\hline Age in years(yrs) & Less than 20 yrs: 25 (6.17) & 20 to 35 yrs: 240 (59.26) & More than 35 yrs: $90(22.22)$ \\
\hline
\end{tabular}

First trimester $=$ first 12 weeks, Second trimester $=13$ to 24 weeks, Third trimester $=24$ weeks onwards, Income class - A = incom

respectively. $6.17 \%(25), 59.26 \%(240)$ and $22.22 \%(90)$ women were of less than 20 years, between 20 to 35 years and more than 35 years of age, respectively. The first antenatal checkup was conducted during the first, second and third trimester of pregnancy in $49.38 \%(200), 44.44 \%(180)$ and $6.17 \%$ (25) of women, respectively. However, less than three, three to five and more than five antenatal visits were attended by $17.28 \%$ (70), $27.16 \%$ (110) and 55.55\% (225) women, respectively.

A total of 700,1086 and 686 number of drugs, with an average of $1.73,2.89$ and 2.49 drugs per pregnant women, were used during first, second and third trimester of pregnancy, respectively [Table 2]. Iron, folic acid, vitamins and calcium were the most frequently used drugs, during all the three trimesters of the pregnancy. During the first trimester-anti-emetics, phenobarbitone, isoxsuprine, progesterone and paracetamol, during the second trimester-antacids, protein supplements, antimicrobials and NSAIDs (nonsteroidal anti-inflammatory drugs) and during the third trimester-phenobarbitone, isoxsuprine, antibiotics, NSAIDs, antiemetics, proton pump inhibitors/ H2 blockers and antihypertensive drugs (nifedipine, methyldopa) were the other commonly used drugs [Table 2].

Category A drugs constituted 55.28\% (387) $87.02 \%(945)$ and $52.48 \%(360)(P<0.001)$ category B constituted $26.57 \%(186), 9.21 \%$ $(100)$ and $33.52 \%(230)(P=0.003)$ and category D constituted 6\% (42), 0.09\% (1) and $12.54 \%(86)(P=0.020)$ of the drugs used during the first, second and third trimester of pregnancy, respectively [Table 3]. However category C drugs constituted $2.90 \%$ (20) of total drugs used during the third trimester and category $X$ drugs constituted $5.71 \%$ (40) of drugs used during the first trimester. Herbal/ homeopathic drugs constituted $6.42 \%$ (45) $3.68 \%(40)$ and $1.46 \%(10)$ of the drugs used in the first, second and third trimester of pregnancy respectively $(P=649)$. Herbal/ homeopathic drugs included multivitamins and iron supplements, calcium, liver tonics, local analgesic ointments, drugs for acidpeptic disease, drugs for leucorrhea and drugs for skin hyper-pigmentation.

It was found that $33.33 \%$ (135) women believed that drug use during pregnancy is dangerous to both mother and child. However, 4.94\% (20) and 20.98\% (85) of women believed that drugs are dangerous for 
Table 2: Pattern of drug use during pregnancy

\begin{tabular}{|c|c|c|c|}
\hline Parameter & $\begin{array}{l}\text { First trimester } \\
(n=405) \\
\text { Number }(\%)\end{array}$ & $\begin{array}{c}\text { Second trimester } \\
(n=375) \\
\text { Number }(\%)\end{array}$ & $\begin{array}{l}\text { Third trimester } \\
(n=275) \\
\text { Number }(\%)\end{array}$ \\
\hline Exposure to $\mathrm{X}$-rays & $20(4.9)$ & & \\
\hline $\begin{array}{l}\text { USG } \\
\text { Drugs used during nreanancy }\end{array}$ & $50(12.35)$ & $-160(42.67)$ & $-10(3.63)$ \\
\hline \multicolumn{4}{|l|}{ Drugs used during pregnancy: } \\
\hline Average/pregnant women & 1.73 & 2.89 & 2.49 \\
\hline Vitamins & $95(13.57)$ & $120(11.05)$ & \\
\hline Iron & $85(12.14)$ & $315(29.00)$ & $160(23.32)$ \\
\hline Folic acid & $130(18.57)$ & $160(14.73)$ & 120 (17.49) \\
\hline Calcium & $60(8.57)$ & $305(28.08)$ & 75 (10.93) \\
\hline Paracetamol & $30(4.28)$ & & $10(1.46)$ \\
\hline NSAIDs & & $30(2.76)$ & $35(5.10)$ \\
\hline Isoxsuprine & $35(5.00)$ & & $55(8.02)$ \\
\hline Phenobarbitone & $40(5.71)$ & & 85 (12.39) \\
\hline Ant acids & $17(2.43)$ & $45(4.14)$ & \\
\hline Anti-emetics & $90(12.85)$ & & $25(3.64)$ \\
\hline PPIs/H2 blockers & & $10(0.92)$ & $25(3.64)$ \\
\hline Antibiotics & $26(3.71)$ & $5(0.46)$ & $40(5.83)$ \\
\hline Antiprotozoals & - & $5(0.46)$ & - \\
\hline Protein supplements & - & $40(3.68)$ & - \\
\hline Progesterone & $40(5.71)$ & & \\
\hline Nifedipine & - & - & $20(2.91)$ \\
\hline Methyldopa & & & $15(2.18)$ \\
\hline & $45(6.42)$ & $40(3.68)$ & $10(1.46)$ \\
\hline \multicolumn{4}{|l|}{ Drugs for chronic illness } \\
\hline Insulin & $5(0.71)$ & $5(0.46)$ & $5(0.73)$ \\
\hline Thyroxin & & $5(0.46)$ & $5(0.73)$ \\
\hline Anti-epileptics & $2(0.28)$ & $1(0.09)$ & $1(0.14)$ \\
\hline
\end{tabular}

First trimester $=$ first 12 weeks, Second trimester $=13$ to 24 weeks, Third trimester $=24$ weeks onwards, $n=$ number, NSAIDs First trimester $=$ first 12 weeks, Second trimester $=13$ to 24 weeks, Third trimester $=24$ weeks
Nonsteroidal anti-inflammatory drugs, PPI = proton pump inhibitors, USG $=$ ultrasonography.

Table 3: Different categories of drug used during pregnancy

\begin{tabular}{lcccc}
\hline Category of drugs & $\begin{array}{c}\text { First trimester } \\
(\text { t.n.d 700) } n(\%)\end{array}$ & $\begin{array}{c}\text { Second trimester } \\
(\text { t.n.d 1086) } n(\%)\end{array}$ & $\begin{array}{c}\text { Third trimester } \\
(\text { t.n.d 686) } n(\%)\end{array}$ & $P$-value* \\
\hline A & $387(55.28)$ & $945(87.02)$ & $360(52.48)$ & $<0.001$ \\
B & $186(26.57)$ & $100(9.21)$ & $230(33.52)$ & 0.003 \\
D & $42(6.00)$ & $1(0.09)$ & $86(12.54)$ & 0.020 \\
C & - & - & $20(2.90)$ & - \\
X & $40(5.71)$ & $40(3.68)$ & $10(1.46)$ & 0.649 \\
Others & $45(6.42)$ & & & \\
(herbal and homeopathic) & & & &
\end{tabular}

Category $\mathrm{A}=$ multivitamins, iron, folic acid, calcium, thyroxin. Category $\mathrm{B}=$ paracetamol, diclofenac sodium, ibuprofen, antacids, metaclopropamide, dicyclomine, rantidine, femotidine, omeprazole, pentaprazole, ampicillin, amoxicillin, cephalosporins, metronidazole, insulin, methyl DOPA. Category $C=$ Nifedipine, Category $D=$ phenobarbitone, carbamazepine, phenytoin. Category
$x=$ progesterone, first trimester $=$ first 12 weeks, second trimester $=13$ to 24 weeks, third trimester $=24$ weeks onwards, tn. $d=$ $\mathrm{x}=$ progesterone, first trimester $=$ first 12 weeks, second trimester $=13$ to 24 weeks, third trimester $=24$ weeks onwards, t.n
total number of drugs, $\mathrm{n}(\%)=$ number(percentage). ${ }^{*} P$-value was calculated after comparing values of first, second and third trimester by using chi-square test with degree of freedom $=2$ and $P$ value $<0.05$ was considered significant.

mother and child/foetus, respectively [Table 4]. $20.98 \%$ (85) women believed that drugs are more dangerous during the first trimester, whereas, $37.03 \%$ (150) believed that drugs are dangerous if consumed at any time

throughout pregnancy. However, only 55.55\% (225) females advocated the use of iron/folic acid during pregnancy. Use of calcium, antacids, NSAIDs and antiallergics was advocated by $27.16 \%$ (110), $20.98 \%$ (85),

Table 4: Knowledge of study population (405) regarding drug use during pregnancy

\begin{tabular}{|c|c|c|c|}
\hline Parameter & Number of women (\%) & Number of women (\%) & Number of women (\%) \\
\hline $\begin{array}{l}\text { Drugs are dangerous if } \\
\text { consumed during } \\
\text { Irrational drug use in }\end{array}$ & $\begin{array}{l}\text { First TM: } 85(20.98), \\
\text { Through out }=150(37.03)\end{array}$ & Second TM:10 (2.47) & Third TM: 0 \\
\hline pregnancy is dangerous to: & Mother $=20(4.94)$ & Child/ Foetus $=85(20.98)$ & Both $=135(33.33)$ \\
\hline $\begin{array}{l}\text { Drugs should be used } \\
\text { in pregnancy: }\end{array}$ & Response - yes & Response - no & Response - no \\
\hline Iron/folic acid & $225(55.55)$ & $23(5.68)$ & $157(38.76)$ \\
\hline Laxatives & $30(7.40)$ & $79(19.50)$ & 296 (73.08) \\
\hline Antacids & 85 (20.98) & $122(30.12)$ & 198 (48.88) \\
\hline Calcium & $110(27.16)$ & $89(21.97)$ & $206(50.86)$ \\
\hline Antiemetics & $10(2.47)$ & 85 (20.98) & $310(76.54)$ \\
\hline Sedatives & $15(3.70)$ & $122(30.12)$ & $268(66.17)$ \\
\hline NSAIDs & 45 (11.11) & $32(7.90)$ & 328 (80.98) \\
\hline Antibiotics & $25(6.17)$ & $190(46.91)$ & $190(46.91)$ \\
\hline Antiallergics & $45(11.11)$ & $67(16.54)$ & $293(72.34)$ \\
\hline Ayurvedic & $35(8.64)$ & $34(8.39)$ & $336(82.96)$ \\
\hline Homeopathic drugs & $29(7.16)$ & $34(8.39)$ & $342(84.44)$ \\
\hline cough /cold remedies & $38(9.38)$ & $110(27.16)$ & $257(63.45)$ \\
\hline Knowledge about & $\mathrm{OC}=235(58.02)$ & Injectibles $=60(14.81)$ & Barrier methods \\
\hline contraception & IUCDs $=145(35.80)$ & & $=100(24.69)$ \\
\hline
\end{tabular}

$T M=$ timester, first trimester $=$ frst 12 weeks, Second trim

$11.11 \%(45)$ and $11.11 \%(45)$ of women, respectively, whereas, use of antiemetics, sedatives, antibiotics, cold and cough remedies and herbal/homeopathic drugs was advocated by less than $10 \%$ of women [Table 4]. 58.02\% (235) females had knowledge about oral contraceptives and only $24.69 \%$ (100) of women had knowledge about barrier contraceptives [Table 4].

On evaluating the effect of education on various parameters, it was found that selfmedication and homeopathic/ herbal drugs were used more in graduates, than in undergraduates $(P<0.001$ and 0.044 respectively) [Table 5]. The percentage of women having knowledge about contraceptives and attending more than five antenatal visits, was more in graduates than in undergraduates [Table 5]. More percentage of graduates advocated the use of iron/folic $\mathrm{acid} /$ calcium supplements during pregnancy, than in undergraduates $(P<0.001)$. Iron, folic acid, vitamins, calcium, paracetamol, antacids, NSAIDs, anti-emetics, H2 blockers and herbal drugs, were frequently consumed as self-medication.

Similarly, on evaluation of the drug utilization pattern in relation to socioeconomic variations, self-medication, homeopathic/ herbal drug use and knowledge about contraceptives were found to be more in the higher socioeconomic status (income class $B$ and $C$ ), than in the lower socioeconomic status (income class-A) [Table 5]. More women from the higher socioeconomic class advocated for the use of iron/folic acid/ calcium supplements during pregnancy, than the lower socioeconomic class [Table 5].

\section{DISCUSSION}

Rational drug use in pregnancy requires the balancing of benefits and potential risks associated with the use of the drug. The 
Table 5: Impact of education and economic status on various parameters related to drug use during pregnancy

\begin{tabular}{|c|c|c|c|c|c|c|c|}
\hline Parameters & $\begin{array}{c}\text { Graduates } \\
(185) \\
\text { number (\%) }\end{array}$ & $\begin{array}{c}\text { Undergraduates } \\
(220) \\
\text { number (\%) }\end{array}$ & $P$-value* & $\begin{array}{c}\text { Income C.A } \\
(205) \\
\text { number (\%) }\end{array}$ & $\begin{array}{c}\text { Income } C . B \\
(155) \\
\text { number (\%) }\end{array}$ & $\begin{array}{c}\text { Income C.C } \\
(45) \\
\text { number (\%) }\end{array}$ & $P$-value ${ }^{t}$ \\
\hline $\begin{array}{l}\text { Self medication } \\
\text { Practices }\end{array}$ & $165(89.18)$ & $78(35.45)$ & $<0.001$ & $79(38.53)$ & $125(80.64)$ & $39(86.67)$ & $<0.001$ \\
\hline $\begin{array}{l}\text { Use of homeopathic/ } \\
\text { herbal drugs }\end{array}$ & $42(22.70)$ & $18(8.18)$ & 0.044 & $16(7.80)$ & 28 (18.06) & $18(40)$ & $<0.001$ \\
\hline $\begin{array}{l}\text { Anti-natal visits attended: } \\
<3\end{array}$ & $12(6.48)$ & $58(26.36)$ & 0.002 & 49 (23.90) & $21(13.54)$ & - & $<0.001$ \\
\hline 3-5 & 44 (23.78) & $66(30)$ & 0.805 & $44(21.46)$ & 52 (33.54) & $14(31.11)$ & 0.102 \\
\hline & $129(69.73)$ & 96 (43.63) & 0.003 & $112(54.63)$ & $82(52.90)$ & $31(68.88)$ & 0.273 \\
\hline $\begin{array}{l}\text { Knowledge about } \\
\text { contraceptives } \\
\text { (any form) }\end{array}$ & $175(94.59)$ & $110(50)$ & $<0.001$ & $92(44.87)$ & 138 (89.03) & $45(100)$ & $<0.001$ \\
\hline $\begin{array}{l}\text { Advocated use of } \\
\text { iron/folic acid/calcium } \\
\text { during pregnancy }\end{array}$ & $155(83.78)$ & 70 (31.81) & $<0.001$ & $35(17.07)$ & $145(93.54)$ & $45(100)$ & $<0.001$ \\
\hline
\end{tabular}

Income C.A = per capita Rs. 500-999, Income C.B = per capita Rs. 1000-2500, Income C.C = per capita > Rs. 2500. ${ }^{*} P$-value was calculated after comparing values between graduates and undergraduates by using chi-square test with degree of freedom $=1$, ${ }_{+} P$-value was calculated after comparing values of three income groups by using chi-square test with degree of freedom $=2$ and $P$-value $<0.05$ was considered significant.

benefits of rational drug use during pregnancy are not only restricted to the recovery of maternal health, but are also helpful in the development of the fetus. By appropriate treatment of conditions like diabetes mellitus and infectious diseases of genital organs, embryopathies, preterm births and abortions could be prevented. ${ }^{[5,6]}$ In our study, iron, folicacid, calcium and vitamins were the most frequently used drugs in pregnancy, with an average of 1.73 to 2.89 drugs per pregnant women. Phenobarbitone, isoxsuprine, progesterone, paracetamol, NSAIDs, antibiotics, anti-emetics, proton pump inhibitors/H2 blockers, antacids and antihypertensive drugs (nifedipine, methyldopa) were the other commonly used drugs. Periconceptional folic-acid supplementation can prevent most neuraltube defects and other congenital abnormalities of the cardiovascular system, urinary tract and limb deficiencies. ${ }^{[7-10]}$ Moreover, folic-acid supplementation in pregnancy is associated with the decreased incidence of habitual spontaneous abortion and pregnancy complications (e.g., placental abruption and preeclampsia). ${ }^{[4,15]}$ However, women (130, 160 and 120 women in the first, second and third trimester, respectively) in the present study.

A similar trend with drug use in pregnancy, was reported from other parts of the world. In a prospective survey in Southwestern Finland, iron and vitamin supplementation were the most frequently used drugs, followed by analgesics, tocolytic agents and drugs for chronic conditions and common pregnancy symptoms. ${ }^{[11]}$ In another study from Australia, folate $(70 \%)$, iron $(38 \%)$ and multivitamins $(27 \%)$ were the most frequently taken drugs by pregnant women; along with herbal drugs like, ginger (20\%) and raspberry leaf $(9 \%) .{ }^{[12]}$ In the present study, ayurvedic / homeopathic drugs constituted $6.42,3.68$ and $1.46 \%$ of total drugs used during the first, second and third trimester of pregnancy, respectively. A folic-acid was taken by less than $50 \%$ of similar trend for use of herbal drugs like cannabis, ginger, raspberry leaf etc. during pregnancy, was reported from other countries. $^{[12,13]}$

In the present study, use of herbal/ homeopathic drugs was reported significantly more in graduates than in undergraduates and more in the high socio-economic class than in the lower. Earlier, a study from Norway reported herbal drug use by $36 \%$ pregnant women and factors like prior use of herbs, high knowledge about herbal drugs and age between 26 and 35 years, were associated with it. ${ }^{[16]}$

Herbal preparations are classified as dietary supplements by FDA and are not regulated like conventional drugs. There is always a threat of interaction between herbal drugs and other medications, potentially making them less active or less safe. ${ }^{[17]}$

The majority of the drugs used during pregnancy in the present study, were from category-A, followed by category-B and category-D.5.71\% and $2.90 \%$ of drugs used during the first and third trimester, were from category- $X$ and category-C, respectively. There are reports of use of potentially harmful drugs (category D drugs $-1.5 \%$ to $4.8 \%$ and category $X$ drugs -2.3 to $4.6 \%$ ) during pregnancy from other developed and underdeveloped countries of the world. . $^{[3,18-20]}$ In a retrospective, register-based cohort study in Finland, it was found that $20.4 \%$ of women purchased at least one drug classified as potentially harmful during pregnancy and $3.4 \%$ purchased at least one drug classified as clearly harmful. ${ }^{[21]}$ According to the
HIMAGE study from France, $4.6 \%$ of women were exposed to drugs (mainly NSAIDs), involved in risk during pregnancy. ${ }^{[22]}$ In a study from Bratislava and Nitra, it was reported that a vast majority of prescribed drugs during pregnancy, belonged to category-C. ${ }^{[23]}$

In the present study, use of OTC (over the counter) drugs as self medication, was reported significantly more in graduates than in undergraduates; as well as more in the higher economic class, than in the lower. Earlier also, in a study from USA, OTC medications (e.g., ibuprofen) that are contraindicated in pregnancy, were used a unexpectedly high rates during pregnancy. ${ }^{[24]}$ In a similar study on general public according to 36,19 and $5 \%$ of the respondents, the use of common OTC drugs during pregnancy represents a small risk, a great risk and completely risk-less picture, respectively. ${ }^{[25]}$ In an epidemiological study, NSAID use during conception or during pregnancy in $5 \%$ women, was associated with an $80 \%$ increased risk of miscarriage. ${ }^{[26]}$

Pregnant women using necessary drug treatments may suffer permanent psychological stress due to the anxiety and fear created by the notion, that nearly all drugs cause congenital abnormality. A study from Hungary reported that 3,000 pregnancies were terminated during the firs trimester, due to a medical indication connected to drug use during pregnancy. ${ }^{[1]}$ In the present study, $33.33 \%$ women believed that drug use during pregnancy is dangerous to both mother and child and $37.03 \%$ women believed that drugs are dangerous if consumed at any time throughout pregnancy. 
However, progesterone, classified as a category- $X$ drug used during the first trimester, was not associated with a teratogenic effect. Similarly, there are various other lacunae in the FDA classification, for foetal risk. Many drugs in category-D were classified, considering the general similarity of the chemical structure. However, mild differences in the chemical structure can change the teratogenic potential, for example the teratogenic oxytetracyclines and nonteratogenic doxycycyline, within the group of tetracyclines. ${ }^{[1]}$

In the existing scenario, knowledge about barrier contraceptives is important to prevent HIV infections and various sexually transmitted diseases, in women of childbearing age. However, in the present study, only $24.69 \%$ women had knowledge about barrier methods. Graduates and women from the higher socioeconomic class have more knowledge about contraceptives, than undergraduates and women from lower socioeconomic class. A previously published study also reported more use of spacing methods in educated couples $(80 \%)$ after the birth of their first child, than uneducated couples $(50 \%$ even after birth of their third child). ${ }^{[27]}$

There is a need to educate and council women of child-bearing age regarding advantages and disadvantages of drug use during pregnancies, with a special reference to alternative therapies and self-medication. Even the doctors need to be trained to give rational treatment to the pregnant women, by including community pharmacology studies in their academic curriculum. Earlier, a study from Canada had demonstrated significant improvement in preventive care, continuity of care and, indicators of diagnostic performance in doctors, after transition from a traditional curriculum to a communityoriented problem- based learning curriculum. ${ }^{[28]}$

In the present study, interviews were held before the pregnancy outcome is known, thereby minimizing the bias of recall. However, inability to know the effect of drugs on pregnancy outcome, as well as inability to study the effect of factors like marital status, history of chronic diseases, bad obstetric history and multiparity or nulli-parity on the pattern of the drug use, could be considered as lacunae of the study. The present study has included tertiary care hospital-based sample; however, conditions could be worst in the remote and rural areas of India. Hence, such periodic studies are further required in diverse environmental, social, educational and cultural conditions, so that the therapeutic guidelines could be revised accordingly, to give rational care to the community.

\section{REFERENCES}

1. Banhidy F, Lowry RB, Czeizel AE. Risk and Benefit of Drug Use During Pregnancy. Int J Med Sci 2005;2:100-6.

2. Sharma R, Verma U, Sharma CL, Kapoor B. Selfmedication among urban population of Jammu city. Indian J Pharmacol 2005;37:37-45.

3. Carmo TA, Nitrini SM. Drug prescription for pregnant women: A pharmacoepidemiological study. Cad Saude Publica 2004;20:1004-13.

4. Drugs in Pregnancy and Lactation, $5^{\text {th }}$ ed. Wilkins and Wilkin: Baltimore; 1998.
5. Nielsen GL, Norgaard B, Puho E, Rothman KJ, Sørensen HT, Czeize AE. Risk of specific congenital abnormalities in offspring of women with diabetes. Diabet Med 2005;22:693-6.

6. Czeizel AE, Toth M, Rockenbauer M. No teratogenic effect after clotrimazole therapy during pregnancy. Epidemiology 1999;10:437-40.

7. Czeizel AE, Dudás I. Prevention of the first occurrence of neural-tube defects by periconceptional vitamin supplementation. $\mathrm{N}$ Engl J Med 1992;327:1832-5.

8. Czeizel AE. Prevention of congenital abnormalities by periconceptional multivitamin supplementation. Br J Med 1993;306:1645-8.

9. Czeizel AE. Reduction of urinary tract and cardiovascular defects by periconceptional multivitamin supplementation. Am J Med Genet 1996;62:179-83.

10. Czeizel AE, Dobo M, Vargha P. Hungarian cohortcontrolled trial of periconceptional multivitamin supplementation shows a reduction in certain congenital abnormalities. Br Defect Res (Part A) 2004;70:853-61.

11. Heikkila AM, Erkkola RU, Nummi SE. Use of medication during pregnancy-A prospective cohor study on use and policy of prescribing. Ann Chir Gynaecol Suppl 1994;208:80-3.

12. Maats FH, Crowther CA. Patterns of vitamin, mineral and herbal supplement use prior to and during pregnancy. Aust N Z J Obstet Gynaecol 2002;42:494-6.

13. Westfall RE, Janssen PA, Lucas P, Capler R. Survey of medicinal cannabis use among childbearing women: Patterns of its use in pregnancy and retroactive self-assessment of its efficacy against 'morning sickness. Compl Ther Clin Pract 2006;12:27-33.

14. Scholl TO, Johnson WG. olic acid:influence on the outcome of pregnancy. Am J Clin Nutr 2000;71:1295S-303.

15. Hernandez-Diaz S, Werler MM, Louik C, Mitchell AA. Risk of gestational hypertension in relation to folic acid supplementation during pregnancy. Am
J Epidemiol 2002;156:806-12.

16. Nordeng $H$, Havnen GC. Impact of socio demographic factors, knowledge and attitude on the use of herbal drugs in pregnancy. Acta Obstet Gynecol Scand 2005;84:26-33.

17. During Your Pregnancy: Is It Safe to Take Herbal Supplements. www.marchofdimes.com/pnhec/ 159_529.asp - 90k - assessed on 27.03.2006.

18. Andrade SE, Gurwitz JH, Davis RL, Chan KA, Finkelstein JA, Fortman K, et al. Prescription drug use in pregnancy. Am J Obstet Gynecol 2004;191:398-407.

19. Bakker MK, Jentink J, Vroom F, Van Den Berg PB, De Walle HE, De Jong-Van Den Berg LT. Drug prescription pattern before, during and after pregnancy for chronic, occasional and pregnancy related drugs in the Netherlands. $\mathrm{Br} \mathrm{J}$ Obste Gynecol 2006;113:559-68.

20. Riley EH, Fuentes-Afflick E, Jackson RA, Escobar GJ, Brawarsky P, Schreiber M, et al. Correlates of prescription drug use during pregnancy. Womens Health (Larchmt) 2005;14:401-9.

21. Malm H, Martikainen J, Klaukka T, Neuvonen PJ. Prescription of hazardous drugs during pregnancy. Drug Saf 2004;27:899-908.

22. Beyens MN, Guy C, Ratrema M, Ollagnier M. Prescription of drugs to pregnant women in france: The HIMAGE study. Therapie 2003;58:505-11.

23. Tisonova J, Magulova L, Goboova M, Wawruch M, Lassanova M, Bozekova L, et al. Consultation activity of two Slovak centres for pharmacotherapy during pregnancy and lactation. Cas Lek Cesk 2006;145:154-9.

24. Glover DD, Amonkar M, Rybeck BF, Tracy TS Prescription, over-the-counter and herbal medicine use in a rural, obstetric population. Am J Obste Gynecol 2003;188:1039-45.

25. Drhova L. Knowledge, attitudes and behaviour of the population of the Czech Republic to selfmedication-II. Knowledge of and information about drugs. Ceska Slov Farm 2005;54:168-72.

26. Li DK, Liu L, Odouli R. Exposure to non-steroidal anti-inflammatory drugs during pregnancy and risk 
of miscarriage: Population based cohort study. $\mathrm{Br}$ Med J 2003;327:68.

27. Takkar N, Goel P, Saha PK, Dua D. Contraceptive practices and awareness of emergency contraception in educated working women. Indian J Med Sci 2005;59:143-9.
28. Tamblyn R, Abrahamowicz M, Dauphinee D, Girard N, Bartlett G, Grand'Maison P, et al. Effect of a community oriented problem based learning curriculum on quality of primary care delivery by graduates: Historical cohort comparison. Br Med J 2005;331:1001-5.

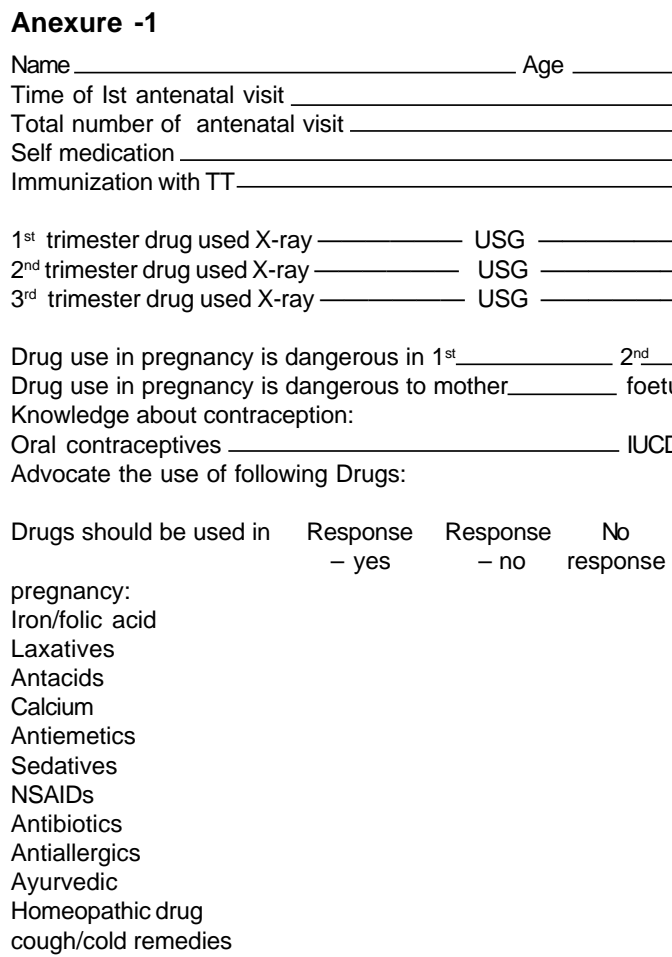

Name Age

Time of Ist antenatal visit

Total number of antenatal visit

Self medication

Immunization with TT

$1^{\text {st }}$ trimester drug used X-ray

USG

$2^{\text {nd }}$ trimester drug used X-ray

USG

$3^{\text {rd }}$ trimester drug used X-ray

USG

Drug use in pregnancy is dangerous in $1^{\text {st }}$ $2^{\text {nd }}$

Drug use in pregnancy is dangerous to mother

Oral contraceptives

Advocate the use of following Drugs:

Drugs should be used in

$\begin{array}{ccc}\text { Response } & \text { Response } & \text { No } \\ \text { - yes } & - \text { no } & \text { response }\end{array}$

pregnancy:

Iron/folic acid

Laxatives

Antacids

Calcium

Antiemetics

Sedatives

NSAIDs

Antibiotics

Antiallergics

Ayurvedic

Homeopathic drug

cough/cold remedies Gravida Income per capita Duration of present pregnancy Treatment for any chronic condition Prescription drug $3^{\text {rd }}$ trimester through out foetus/child both IUCDS Barrier method Injectibles 